\title{
Endophthalmitis: state of the art
}

This article was published in the following Dove Press journal:

Clinical Ophthalmology

8 January 2015

Number of times this article has been viewed

\author{
Kamyar Vaziri \\ Stephen G Schwartz \\ Krishna Kishor \\ Harry W Flynn Jr \\ Department of Ophthalmology, \\ Bascom Palmer Eye Institute, \\ University of Miami Miller School \\ of Medicine, Miami, FL, USA
}

\begin{abstract}
Endophthalmitis is an uncommon diagnosis but can have devastating visual outcomes. Endophthalmitis may be endogenous or exogenous. Exogenous endophthalmitis is caused by introduction of pathogens through mechanisms such as ocular surgery, open-globe trauma, and intravitreal injections. Endogenous endophthalmitis occurs as a result of hematogenous spread of bacteria or fungi into the eye. These categories of endophthalmitis have different risk factors and causative pathogens, and thus require different diagnostic, prevention, and treatment strategies. Novel diagnostic techniques such as real-time polymerase chain reaction (RT-PCR) have been reported to provide improved diagnostic results over traditional culture techniques and may have a more expanded role in the future. While the role of povidone-iodine in prophylaxis of postoperative endophthalmitis is established, there remains controversy with regard to the effectiveness of other measures, including prophylactic antibiotics. The Endophthalmitis Vitrectomy Study (EVS) has provided us with valuable treatment guidelines. However, these guidelines cannot be directly applied to all categories of endophthalmitis, highlighting the need for continued research into attaining improved treatment outcomes.
\end{abstract}

Keywords: endophthalmitis, exogenous, endogenous, postoperative, intravitreal injection

\section{Introduction}

Endophthalmitis is a rare but potentially sight-threatening disease characterized by marked inflammation of intraocular tissues and fluids. ${ }^{1}$ This ocular pathology can be divided into broad categories of exogenous and endogenous endophthalmitis. Exogenous endophthalmitis is caused by inoculation of the eye by microorganisms from the external environment and most commonly occurs as a complication of ocular surgery, trauma, or intravitreal injections. ${ }^{1}$ Endogenous endophthalmitis is caused by hematogenous spread of infectious organisms from distant sites of the body. Both categories of endophthalmitis lead to subsequent intraocular inflammation and potentially severe visual loss. ${ }^{2}$

\section{Classification of endophthalmitis Acute-onset postoperative endophthalmitis Background and incidence}

Acute-onset postoperative endophthalmitis (Figure 1) is generally defined as occurring within 6 weeks of an ocular procedure. Cataract surgeries are responsible for the majority of these cases. ${ }^{3,4}$ The reported incidence of acute-onset postoperative endophthalmitis following cataract surgery ranges from $0.03 \%$ to $0.2 \% .^{5-12}$ Less commonly, acute-onset postoperative endophthalmitis has been reported following other ocular procedures including penetrating keratoplasty, ${ }^{5,13,14}$ scleral buckling, ${ }^{15}$ glaucoma drainage device implantation, ${ }^{16}$ and others.

Due to increasing utilization of pars plana vitrectomy (PPV), ${ }^{17}$ there is increasing interest in endophthalmitis following this type of surgery. Reported incidence rates
Correspondence: Stephen G Schwartz Bascom Palmer Eye Institute, University of Miami Miller School of Medicine, 3II 9th Street North, \#100, Naples, FL 34I02, USA

Tel +l 2396593937

Fax +I 2396593982

Email sschwartz2@med.miami.edu 


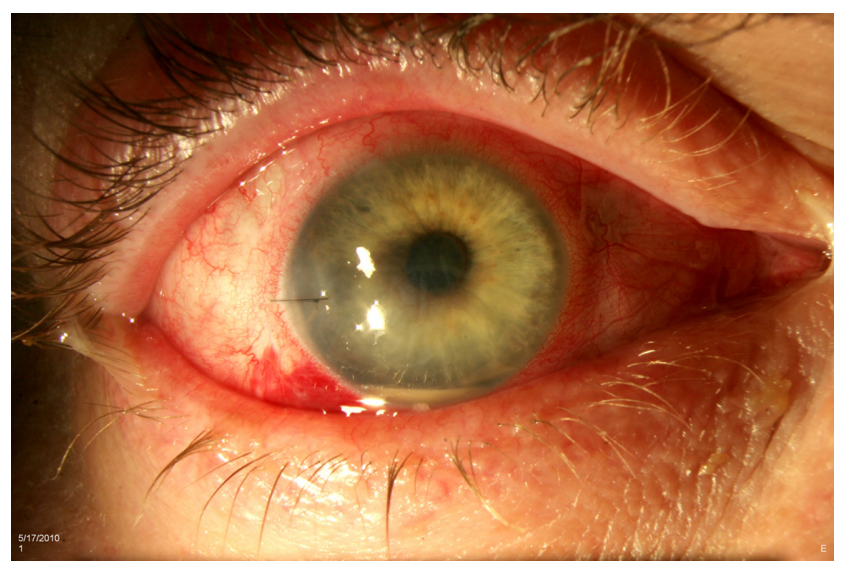

Figure I Acute-onset postoperative endophthalmitis (note the sutured corneal wound and hypopyon).

range from $0 \%$ to $2.4 \%$ for $20 \mathrm{G}$ surgeries (with most rates falling between $0.02 \%$ and $0.05 \%$ ) and $0 \%-1.3 \%$ following $23 \mathrm{G}$ and $25 \mathrm{G}$ PPV. ${ }^{18-23}$

\section{Presentation}

In the Endophthalmitis Vitrectomy Study (EVS), ${ }^{24} 94 \%$ of patients with acute-onset postoperative endophthalmitis following cataract surgery or secondary intraocular lens (IOL) implantation presented with decreased visual acuity, $82 \%$ with conjuctival injection, $74 \%$ with eye pain, and approximately $35 \%$ with eyelid edema. Acute-onset postoperative endophthalmitis following other types of surgery present with same general signs, to varying degrees. ${ }^{22,25}$

\section{Risk factors}

Among patients undergoing cataract surgery, preoperative risk factors associated with acute-onset postoperative endophthalmitis include blepharitis, diabetes mellitus, and older age. ${ }^{12,26-30}$ Perioperative risk factors include preoperative steroids, intraoperative complications, posterior capsular rupture, vitreous loss, and surgeons with less experience. ${ }^{11,26,27,29-36}$ Some series have reported clear corneal incisions and lack of intracameral antimicrobials as risk factors but these are controversial. Postoperative risk factors include inpatient status and wound leak on postoperative day $1.37,38$

\section{Causative organisms}

The EVS recruited only patients with suspected bacterial endophthalmitis. The investigators reported that among culture-positive cases, $94.2 \%$ of isolates were Gram-positive bacteria. ${ }^{24}$ Among these, coagulase-negative staphylococci were the most commonly identified pathogens (70\%) followed by Staphylococcus aureus (9.9\%) and Streptococcus species $(9 \%) .{ }^{24}$ Coagulase-negative Staphylococcus species have also been the predominant isolates reported in endophthalmitis following PPV. ${ }^{21,22}$

There were no reported cases of acute-onset postoperative fungal endophthalmitis in the EVS and other US-based studies. ${ }^{5,39}$ However, two publications from India reported a high incidence of postoperative fungal endophthalmitis ranging from $17 \%$ to $22 \%$. $^{40,41}$

\section{Delayed-onset postoperative endophthalmitis}

\section{Background and incidence}

Delayed-onset (chronic) postoperative endophthalmitis (Figure 2) is generally defined as occurring more than 6 weeks after surgery. ${ }^{42}$ A recent study reported a mean of 343 days from the date of surgery to the date of diagnosis. ${ }^{43}$ Delayed-onset postoperative endophthalmitis is less common than the acute-onset category with a reported ratio of approximately 1:3.5. ${ }^{43}$ Similarly, delayed-onset post-cataract endophthalmitis was reported to account for only $7.2 \%$ of all postoperative endophthalmitis cases. ${ }^{3}$ The incidence of delayed-onset postoperative endophthalmitis has been reported at $0.02 \%{ }^{44}$

\section{Presentation}

Delayed-onset postoperative endophthalmitis typically progresses slowly and may involve only mild inflammation. ${ }^{43}$ When compared with acute-onset type, delayed-onset postoperative endophthalmitis is less commonly associated with hypopyon. Pain may or may not be present. Characteristic white plaques within the capsular bag are frequently seen. ${ }^{43}$

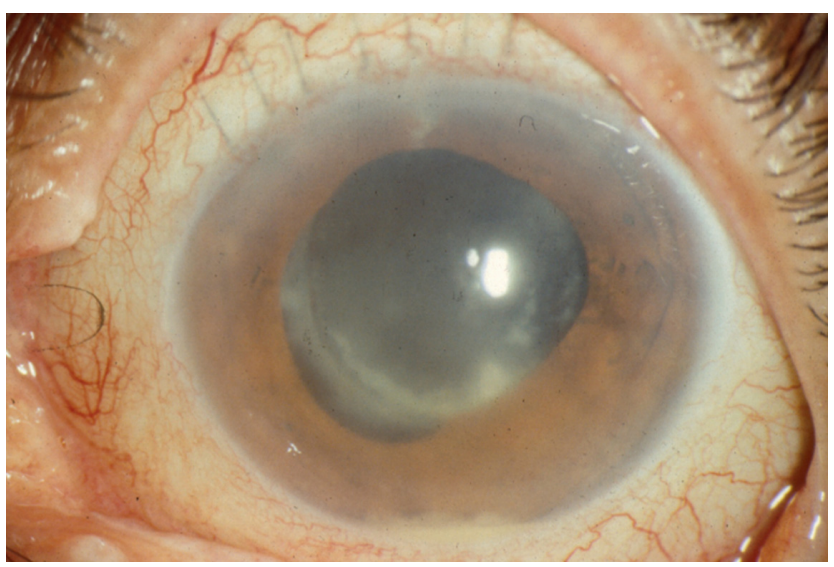

Figure 2 Delayed-onset (chronic) postoperative endophthalmitis (note the small hypopyon and peripheral intracapsular infiltrates). 


\section{Causative organisms}

Propionibacterium acnes is the most common microorganism isolated in culture-positive cases of chronic postoperative endophthalmitis, accounting for $41 \%-63 \%$ of cases. ${ }^{43-45}$ Fungal infections are also important causative pathogens and are responsible for $16 \%-27 \%$ of cases. ${ }^{43-45}$

\section{Bleb-associated endophthalmitis}

\section{Background and incidence}

Bleb-associated endophthalmitis (Figure 3) may occur following trabeculectomy in either an acute $(<4$ weeks) or more commonly delayed ( $>4$ weeks) onset. ${ }^{46}$ The reported mean time from surgery to diagnosis varies but has generally been in the range of approximately 1.5 years $^{47}$ to 7 years ${ }^{48,49}$ and even up to 44 years. ${ }^{50,51}$ The reported incidence rates of bleb-associated endophthalmitis range from $0.17 \%$ to $13.2 \% .^{52-62}$

\section{Presentation}

Bleb-associated endophthalmitis must be differentiated from blebitis, which presents with a purulent filtering bleb, conjuctival injection and discharge along with photophobia, but no hypopyon or vitreous involvement. Bleb-associated endophthalmitis may be associated with pain, decreased visual acuity, relative afferent pupillary defect, and hypopyon. ${ }^{50,63}$ Prodromal symptoms such as headache, browache, and conjunctivitis have been reported in 35\% of cases of bleb-associated endophthalmitis. ${ }^{64}$

\section{Risk factors}

Reported risk factors include a history of previous blebitis, lateonset bleb leak, younger age, use of antimetabolites, inferior trabeculectomy, thin avascular bleb, axial myopia, blepharitis, and chronic antibiotic use..$^{62,64-67}$ While intraoperative use of

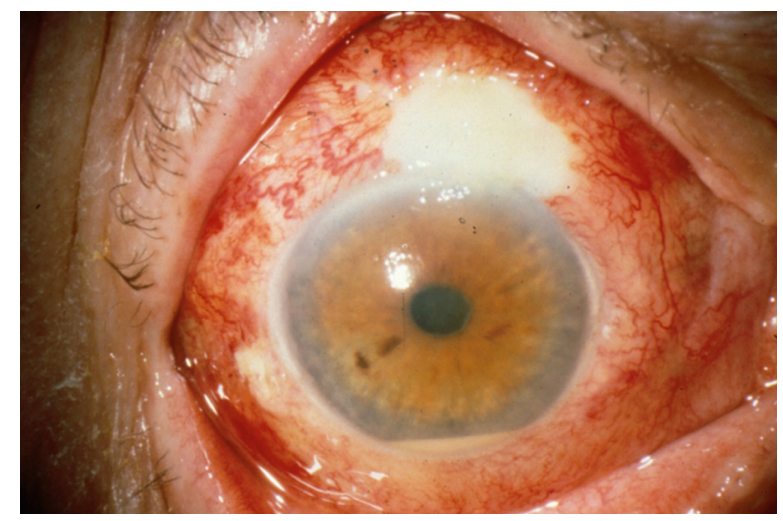

Figure 3 Bleb-related endophthalmitis (note the purulent filtering bleb and hypopyon). antimetabolites (specifically mitomycin C) has significantly increased the success rate of trabeculectomies, ${ }^{68}$ their use has been associated with a 3-fold increased risk of developing endophthalmitis. ${ }^{66,69}$ This increased risk may have been reduced in recent years due to increased surgeons' confidence levels in using intraoperative mitomycin $\mathrm{C}$ and a shift from limbus-based to fornix-based conjuctival flaps. ${ }^{70}$

\section{Causative organisms}

Similar to acute-onset postoperative endophthalmitis, coagulase-negative staphylococci (specifically Staphylococcus epidermidis) and $S$. aureus are the most common isolates in early bleb-associated endophthalmitis. ${ }^{50,60}$ In contrast, Streptococcus species and gram-negative organisms (specifically Moraxella catarrhalis) are the predominant causes of delayed-onset bleb-associated endophthalmitis..$^{50,71}$

\section{Postintravitreal injection endophthalmitis Background and incidence}

The incidence of endophthalmitis following anti-vascular endothelial growth factor (anti-VEGF) injections (Figure 4) has been reported in the range of $0.02 \%-0.32 \%$ per injection. ${ }^{72}$ Because most patients are treated with a series of injections, the incidence rate per patient is higher. A large meta-analysis including 350,535 injections among 45 published studies between 2005 and 2012 reported an overall incidence rate of $0.056 \%$ or 1 per 1,779 intravitreal injections. ${ }^{72}$ The incidence of endophthalmitis following intravitreal injection of triamcinolone acetonide has been reported to be in the range of $0.001 \%-0.87 \%$ per injection, but is generally thought to be higher than that following anti-VEGF injections. ${ }^{73-75}$

Noninfectious endophthalmitis may occur following intravitreal injections. The etiology is poorly understood but may represent an inflammatory reaction to a component in the

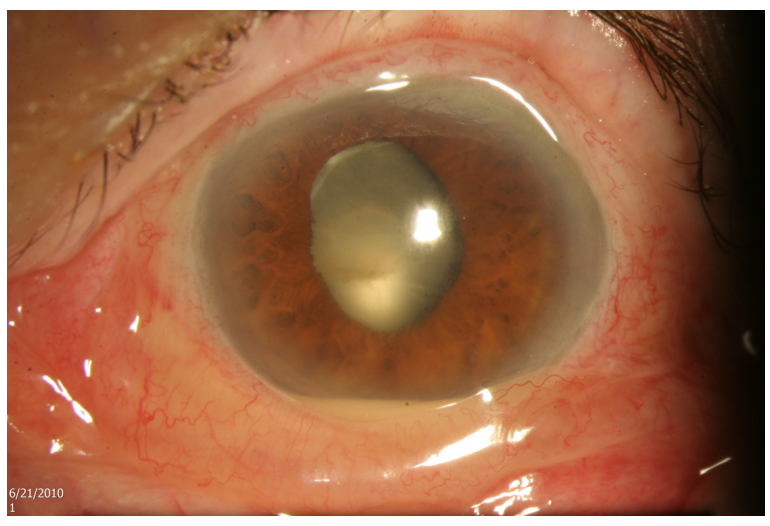

Figure 4 Endophthalmitis following intravitreal injection (note the chemosis and hypopyon). 
medication vehicle or migration of triamcinolone acteonide crystals. ${ }^{76}$ Reported incidence rates of noninfectious endophthalmitis are $0.37 \%$ after aflibercept injections, ${ }^{77}$ $0.27 \%-1.49 \%$ after bevacizumab injections, ${ }^{78-80}$ and $1.6 \%-2.7 \%$ after triamcinolone acetonide injections. ${ }^{81,82}$

\section{Presentation}

Post-intravitreal injection endophthalmitis typically occurs acutely within the first few days. ${ }^{83,84}$ Just like other types of endophthalmitis, the most common presenting signs and symptoms of endophthalmitis following intravitreal injections are decreased vision, eye pain, and redness, with presence of anterior chamber cells, hypopyon, and vitritis. ${ }^{83-86}$

Generally, eye pain, anterior chamber fibrin, and profound visual loss are less common in noninfectious postinjection endophthalmitis than in infectious cases and this could potentially help in distinguishing between the two. ${ }^{76,86}$ However, in a retrospective review of cases with presumed endophthalmitis, substantial overlap was observed in the presenting signs and symptoms of noninfectious versus infectious types. ${ }^{83}$

\section{Risk factors}

Reported risk factors include older age, diabetes mellitus, blepharitis, subconjuctival anesthesia, patient moving/ squeezing during the injection, and the use of compounded medications. ${ }^{87,88}$ Batch-related noninfectious endophthalmitis has also been reported in $27 \%$ and $39 \%$ of patients injected from two specific bevacizumab lots. ${ }^{89}$

\section{Causative organisms}

Two meta-analyses of isolates from endophthalmitis following intravitreal injection of anti-VEGF agents have reported that overall, coagulase-negative Staphylococcus (aggregated mean of 38\%-65\%) and Streptococcus species (29\%-31\%) are the most cultured organisms. ${ }^{72,90}$ Other less common pathogens found are Bacillus cereus, Enterococcus faecalis, S. epidermidis, and S. aureus. While coagulase-negative Staphylococcus species are the most commonly isolated pathogens in both postoperative and postinjection endophthalmitis cases, Streptococcus species are 3 times more prevalent in postinjection endophthalmitis than in postoperative cases. ${ }^{90}$ Of note, Streptococcus species make up $41 \%$ of normal oral flora. ${ }^{91}$ Therefore, the mechanism of infection in postinjection endophthalmitis may involve contamination of the ocular surface by oropharyngeal bacteria. ${ }^{90}$

In multiple series, a large proportion of clinically suspected endophthalmitis cases were culture-negative (aggregated means of $46.5 \%-48 \%)^{72,90}$

\section{Posttraumatic endophthalmitis}

\section{Background and epidemiology}

Posttraumatic endophthalmitis is an uncommon but important complication of open-globe injury (Figure 5) ${ }^{92-94}$ In recent years, the incidence of endophthalmitis following open-globe trauma has been reported to be between $0 \%$ and $12 \%{ }^{95-103}$ with rates as high as $35 \%$ when an intraocular foreign body (IOFB) is present. ${ }^{94}$

\section{Presentation}

The presentation and onset of posttraumatic endophthalmitis vary depending on the mechanism of injury and the virulence of organisms involved. Endophthalmitis can present within hours or can be diagnosed years after the initial injury. ${ }^{104}$ Signs and symptoms include hypopyon, decreased vision, pain out of proportion to the degree of trauma, retinitis, vitritis, retinal necrosis, and periphlebitis. ${ }^{96,104}$ Other findings which could potentially aid the clinician in suspecting endophthalmitis in a case of globe injury include corneal and/or lid edema and loss of red reflex..$^{105}$

\section{Risk factors}

Many predisposing factors have been associated with the development of endophthalmitis following open-globe injuries. These include IOFB, traumatic lens rupture, corneal wound, retinal break/detachment, traumatic cataract/posterior lens rupture, dirty wound, long hospital stay, and rural location. ${ }^{94,95,98,100,101}$ Delayed wound closure and primary repair (beyond 12-24 hours) have also been reported as important risk factors. ${ }^{95,96,106,107}$ Tissue prolapse

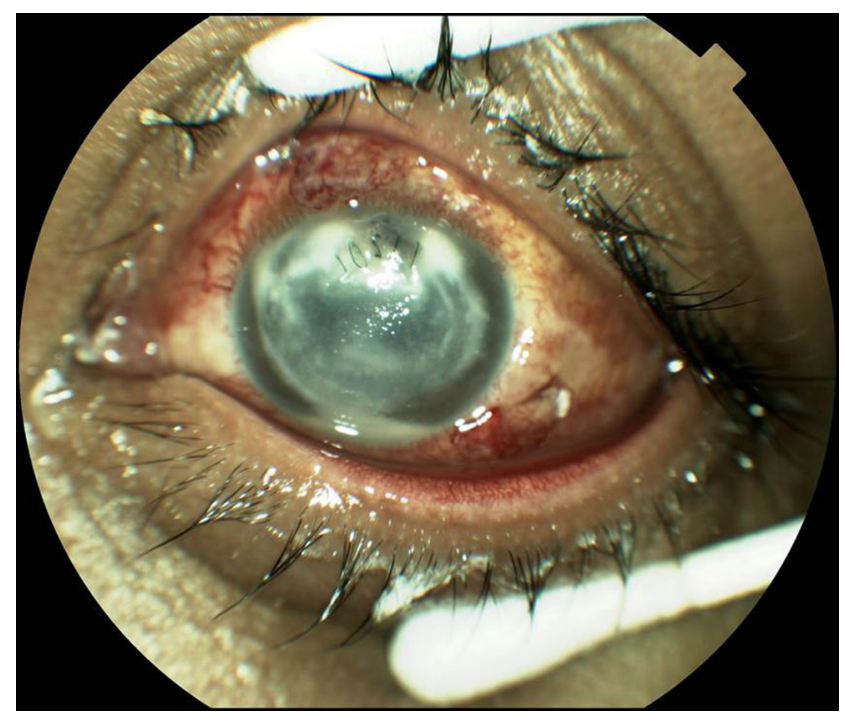

Figure 5 Posttraumatic endophthalmitis (note the sutured corneal wound and hypopyon). 
(iris, vitreous) and presence of hyphema may reduce the risk of endophthalmitis since they may act as a barrier against entrance of microbes. ${ }^{96,100}$

\section{Causative organisms}

Approximately $80 \%-90 \%$ of culture-positive cases are caused by bacteria. ${ }^{108,109}$ Gram-positive cocci are the more common isolates among bacteria, followed by Gram-positive bacilli and other Gram-negative organisms. ${ }^{108,109}$ Among Gram-positive cocci, coagulase-negative Staphylococcal organisms (ie, S. epidermidis and Staphyloccoccus saprophyticus) along with Streptococcus species are the predominant groups. Gram-positive Bacillus species have been commonly reported in culture isolates of posttraumatic endophthalmitis. ${ }^{95,101,108-110}$ Enterobacter and Pseudonomas species are the most common Gram-negative pathogens and Aspergillus species are the most prevalent fungal cause of posttraumatic endophthalmitis. ${ }^{108,109}$

\section{Endogenous endophthalmitis \\ Background and incidence}

In contrast to exogenous endophthalmitis, endogenous endophthalmitis is caused by inoculation of the eye by infectious pathogens spread systemically through the bloodstream and across the blood-ocular barrier. ${ }^{111}$ Endogenous endophthalmitis is uncommon and generally accounts for $2 \%-16 \%$ of all reported endophthalmitis cases ${ }^{92,93,112-114}$ but the prevalence has been reported to be as high as $41 \%$ in one series. ${ }^{115}$

\section{Presentation}

Symptoms of endogenous endophthalmitis include decreased vision, eye pain, eye redness, photophobia, floaters, and eyelid swelling. ${ }^{116-120}$ Reported ocular signs include hypopyon, subconjuctival hemorrhage, conjuctival injection, iritis/retinitis, corneal edema, anterior chamber cells, and reduced or absent red reflex. ${ }^{117,119,121}$

Since the pathogenesis of endogenous endophthalmitis typically involves hematogenous spread of infection to the eye, systemic findings and bilateral involvement are relatively common. Systemic finding would be signs and symptoms associated with sepsis or bacteremia such as fever, chills, and nausea and vomiting. Bilateral involvement of endogenous endophthalmitis has been reported in 19\%-33\% of cases. ${ }^{116-118,120,122}$

\section{Risk factors}

Several studies have reported a high prevalence of comorbidities, which can potentially predispose patients to development of endogenous endophthalmitis. These include immunocompromisation, diabetes mellitus, malignancies, intravenous drug use, organ abscess, immunosuppressive therapy, indwelling catheter, urinary tract infection, organ transplant, end-stage renal or liver disease, and endocarditis. ${ }^{116,118,123-125}$ While most studies evaluating patients with endogenous endophthalmitis have reported predisposing comorbidities, one series reported seven cases of culture proven endogenous endophthalmitis in healthy, immunocompetent individuals without any apparent extraocular loci of infection. ${ }^{126}$

\section{Causative organisms}

The pathogens involved in endogenous endophthalmitis vary from study to study and appear to be potentially affected by geographic location and by the origin of the extraocular loci of infection. In contrast to other types of endophthalmitis where bacteria are the most prevalent pathogens, fungal causes were the most commonly isolated microorganisms in several series of endogenous endophthalmitis. ${ }^{120,122,124,127,128}$ The leading cause of fungal endogenous endophthalmitis is Candida albicans, followed by Aspergillus species. ${ }^{117,118,120,127,128}$

Bacterial endogenous endophthalmitis is typically due to Gram-positive species in western nations. ${ }^{19,120,123,128}$ Meanwhile, Gram-negative species (specifically Klebsiella species) are the main cause of bacterial endogenous endophthalmitis in East Asian countries. ${ }^{111,116,121,129}$

\section{Diagnosis of endophthalmitis Background}

Endophthalmitis is initially suspected based upon clinical presentation, subsequently confirmed with laboratory testing of vitreous or aqueous. It is important to consider potential mimickers of endophthalmitis, including noninfectious inflammation (including toxic anterior segment syndrome), retained lens material, vitreous hemorrhage, and others. While suspected cases of endophthalmitis are typically treated with empiric broad-spectrum antibiotics, identifying the causative microorganisms becomes important in assessing antibiotic susceptibility and also in guiding treatment in cases that do not respond to initial therapy.

Vitreous specimens provide more accurate and reliable culture results than do aqueous cultures. ${ }^{130-133}$ For example, in one series, $48 \%$ of the cases that had a negative aqueous culture showed microbial growth in vitreous cultures. ${ }^{134}$ Vitreous specimens have been traditionally obtained by vitreous tap using a needle and syringe. Other options include using vitrectomy cutters (when PPV is indicated) and office-based automated vitrectors. ${ }^{135,136}$ No difference 
has been shown in the positivity of cultures obtained from vitreous tap versus PPV. ${ }^{133}$

\section{Challenges in diagnosing specific classes of endophthalmitis}

Approximately $70 \%$ of cases of postoperative endophthalmitis yield a positive culture, ${ }^{5,11,134}$ although noninfectious endophthalmitis is relatively more common after intravitreal injection. In a meta-analysis, over $50 \%$ of endophthalmitis cases following anti-VEGF injections were culturenegative. ${ }^{72}$

The diagnosis of posttraumatic endopthalmitis may be challenging as the signs and symptoms of endophthalmitis may overlap with those of the initial injury. As such, the presence of hypopyon, vitritis, and/or worsening pain should be considered possible signs of infection. ${ }^{110,137}$ Another important diagnostic step in posttraumatic endophthalmitis is the use of imaging techniques to identify the presence of occult IOFBs. In one series, IOFB was identified by clinical examination in $46 \%$ of cases, by B-scan echography in $52 \%$, and by computed tomography (CT) in $95 \% .{ }^{138}$ Magnetic resonance imaging (MRI) may be considered after CT scan (so that metallic IOFBs are ruled out) to better identify nonmetallic IOFBs. ${ }^{139}$

In endogenous endophthalmitis, the diagnosis can sometimes be aided by the presence of systemic signs and symptoms of infection and also by blood cultures. However, endogenous endophthalmitis may occur in patients with no overt signs of systemic infection. ${ }^{126}$ In addition, negative blood cultures do not necessarily rule out a diagnosis of endogenous endophthalmitis. In one series, blood cultures were positive in only $33 \%$ of cases while vitreous samples were positive in $87 \%$ of the same patients. ${ }^{128}$

\section{Recent advances in identifying pathogens}

Beyond the use of traditional culture media, there have been recent advances in the rapid and accurate detection of causative bacteria and fungi in endophthalmitis. ${ }^{140}$ Realtime-polymerase chain reaction (RT-PCR) has been utilized to identify both bacteria ${ }^{141,142}$ and fungi. ${ }^{143,144}$ As an example, in one series the rate of detection of bacteria in aqueous and vitreous samples increased from approximately $48 \%$ to over $95 \%$ using PCR. ${ }^{142}$ Other novel microbial detection techniques which could potentially be used in rapid diagnosis of endophthalmitis causes are Matrix-Assisted Laser Desorption Ionization-Time of Flight (MALDI-TOF) Mass Spectrometry ${ }^{145,146}$ and the use of magneto-DNA nanoparticle system. The latter technique was reported to simultaneously identify 13 species of bacteria in under 2 hours. ${ }^{147}$

\section{Treatment of endophthalmitis Acute-onset postoperative endophthalmitis}

The EVS enrolled patients with endophthalmitis following cataract surgery or secondary IOL implantation within 6 weeks of surgery. The EVS reported that in patients with visual acuity of light perception (LP), when compared to tap and inject, prompt PPV was associated with a 3-fold increase in the proportion of patients achieving visual acuity of 20/40 or better, a 2-fold increase in the proportion of patients achieving visual acuity of 20/100 or better, and a decrease in the proportion of patients achieving visual acuity of worse than 5/200. In patients with better than LP initial visual acuity, however, tap and inject had comparable outcomes as PPV. ${ }^{24}$ Based on these results, PPV is generally recommended in patients presenting with LP, and tap and inject is generally recommended for eyes presenting with visual acuity of better than LP.

The role of systemic antibiotics in the treatment of exogenous endophthalmitis remains controversial. The EVS reported that systemic amikacin and ceftazidime had no effect on the final visual outcome. ${ }^{24}$ Fourth-generation fluoroquionolones, which were not tested by the EVS, achieve therapeutic levels from the systemic circulation in the noninflamed eye. ${ }^{148}$ One study compared the use of oral ciprofloxacin versus moxifloxacin in patients with acuteonset postoperative endophthalmitis and reported that the group treated with oral moxifloxacin had a faster resolution of hypopyon and a decreased need for repeat intravitreal antibiotics. ${ }^{149}$

\section{Delayed-onset postoperative endophthalmitis}

The treatment of delayed-onset (chronic) postoperative endophthalmitis is controversial because of the variable clinical presentations and different virulences of the causative organisms. Treatment with PPV combined with partial capsulectomy and injection of intraocular antibiotics led to complete resolution in only $50 \%$ of the cases in one series. ${ }^{150}$ In another series, recurrent disease occurred in more than $70 \%$ of the cases of treated delayed-onset endophthalmitis but when PPV with total capsulectomy and IOL exchange or removal were performed, $90 \%$ had complete resolution of endophthalmitis. ${ }^{43}$ As a result, total capsulectomy and removal of IOL may be considered for recurrent cases. ${ }^{43,151}$ 


\section{Postintravitreal injection endophthalmitis}

To date, there are no randomized clinical trials regarding the treatment of postinjection endophthalmitis. Since the most common isolates in both acute postoperative and postinjection endophthalmitis are Staphylococcus species, many clinicians use the EVS as a guideline for endophthalmitis following intravitreal injections. The role of initial PPV, however, remains unclear in postinjection endophthalmitis. In one series, $90 \%$ of the patients treated with tap and inject regained their preinjection visual acuity, while only $46 \%$ for patients treated with initial PPV did so. ${ }^{152}$

\section{Bleb-associated endophthalmitis}

Streptococcus species and other virulent organisms are relatively more common in bleb-associated endophthalmitis, potentially leading to worse visual outcomes. ${ }^{46,71}$ As a result, more aggressive management, including prompt PPV, has been suggested for the treatment of bleb-associated endophthalmitis. ${ }^{153,154,47,63}$ Alternatively, another study reported that the eyes that underwent initial PPV had worse outcomes, so this question remains unsettled. ${ }^{71}$

\section{Endogenous endophthalmitis}

Management of endogenous endophthalmitis includes a variable combination of systemic and intravitreal antibiotics (or antifungals) and PPV..$^{155}$ In a meta-analysis of endogenous endophthalmitis cases published from 2001 to 2012, 56\% of the cases received systemic antibiotics, $76 \%$ received intravitreal antibiotics (vancomycin most commonly), 12\% received intravitreal corticosteroids, and $32 \%$ of the eyes underwent PPV. ${ }^{119}$ Systemic antibiotics and antifungals (depending on the causative organism) are generally recommended as endogenous endophthalmitis generally has extraocular loci of infection. In a meta-analysis of cases from 1986 to 2012, eyes which underwent PPV were more likely to have a final visual acuity of at least $20 / 200$ and were less likely to progress to enucleation. ${ }^{119}$

\section{Posttraumatic endophthalmitis}

While it is generally agreed that primary closure of an open-globe injury is important, there is no consensus with regards to managing established or suspected posttraumatic endophthalmitis. Similar to bleb-associated endophthalmitis, causative organisms in posttraumatic endophthalmitis are generally more virulent. The high prevalence of Streptococcus and Bacillus species has led to the suggestion of aggressive treatment, including initial PPV when feasible. ${ }^{105,110,154}$ In addition to PPV, a combination of intravitreal, subconjuctival, topical, and systemic antibiotics are also recommended. ${ }^{105,110,156}$

\section{Changing trends in microbial profiles and antibiotic susceptibilities}

Causative organisms evolve over time. For example, cases of fungal endophthalmitis following intravitreal injections were initially very rare but recently there have been reports of these cases in association with compounded triamcinolone acetonide $^{157}$ and compounded bevacizumab. ${ }^{158}$

Two studies have reported that overall, S.epidermidis is the predominant pathogen in cases of endophthalmitis followed by Streptococcus viridans and other coagulase negative Staphylococcus species. ${ }^{3,159}$ Vancomycin for Gram-positive bacteria, ceftazidime for Gram-negative bacteria, and voriconazole for fungal endophthalmitis continue to be effective choices for initial treatment of endophthalmitis. . $^{3,159,160}$

\section{Visual outcomes of endophthalmitis treatment \\ Acute-onset postoperative endophthalmitis}

In the EVS, only $53 \%$ of patients had a final visual acuity of $20 / 40$ or better and $15 \%$ had a final visual acuity of $20 / 200$ or worse. ${ }^{24}$ In a more recent single-center series, $50 \%$ of eyes with acute-onset postoperative endophthalmitis had a final visual acuity of $20 / 40$ or better and overall more than $36 \%$ had a final visual acuity of worse than 20/200. ${ }^{5}$ A large retrospective study reported that eyes with final visual acuity of 20/40 or better were more likely to be culture-negative or culture-positive for coagulase-negative Staphylococci. ${ }^{11}$ In another series, coagulase-negative Staphylococcus was associated with good final visual outcomes (20/40 or better) while Streptococcus species were more prevalent in eyes with worse than $20 / 200$ outcomes. ${ }^{161}$

\section{Delayed-onset postoperative endophthalmitis}

Delayed-onset endophthalmitis has been reported to have generally more favorable final visual outcomes when compared to acute-onset cases: $50 \%$ achieved final vision of better than $20 / 40$ versus $27 \%$ respectively. ${ }^{43}$ A review of 4 case series of delayed-onset endophthalmitis reported that eyes infected with $P$. acnes generally had a better final visual outcome while fungal cases were associated with significantly worse outcomes where more than one-fifth of these cases resulted in final visual acuity of worse than 20/200. ${ }^{162}$ 


\section{Bleb-associated endophthalmitis}

Bleb-associated endophthalmits is also associated with unfavorable final visual outcomes due to high prevalence of virulent pathogens such as Streptococcus species and Gramnegative bacteria. ${ }^{46,71}$ In one series, $35 \%$ of cases had a final visual outcome of no light perception (NLP) and in another study this number was $23 \%{ }^{47,163}$ Initial visual acuity was reported to have a significant correlation with final visual acuity. ${ }^{163}$ In one study, $83 \%$ of patients with initial visual acuity of better than LP had a final visual acuity of better than 20/40 while this degree of improvement was achieved by only $31 \%$ of patients who presented with LP on initial presentation. ${ }^{46}$ Culture positivity with more virulent organisms (such as Streptococcus species) was also correlated with worse visual outcomes. ${ }^{46,163}$

\section{Posttraumatic endophthalmitis}

Posttraumatic endophthalmitis is associated with generally poor outcomes. One series reported a final visual outcome of NLP in $23 \%$ of cases with $45 \%$ of cases with hand motions (HM) or worse. ${ }^{102}$ Recent studies have reported that a final visual acuity of $20 / 40$ or better was achieved in only $15 \%-40 \%$ of cases with posttraumatic endophthalmitis. ${ }^{95,98,164,165}$ One series reported that a good final visual outcome (defined as $20 / 45$ or better) was significantly associated with initial visual acuity of at least LP and an absence of a pupillary fibrin membrane. ${ }^{165}$

\section{Endogenous endophthalmitis}

A meta-analysis reported that among endogenous endophthalmitis case series between 2001 and 2012 (a total of 89 eyes), $41 \%$ had a final visual acuity of at least $20 / 200$ and $19 \%$ underwent enucleation or evisceration. These visual outcomes were improved compared to cases treated prior to 2001, in which final visual acuity of at least 20/200 was seen in only $31 \% .{ }^{119}$ Among the three broad categories of pathogens found in endogenous endophthalmitis (bacterial, yeast, and molds), cases caused by molds (Aspergillus species) are associated with the worst final visual outcomes and cases caused by yeasts (Candidia species) with the best. In one study, despite appropriate therapy, $25 \%$ of cases of endogenous endophthalmitis caused by Aspergillus species required enucleation while there were no enucleated cases with Candida isolates. ${ }^{155}$ In other studies cases caused by Aspergillus were associated with poorer final visual outcomes. ${ }^{120}$ In another series, while $80 \%$ of cases caused by Candidia had a final visual acuity of at least 20/200, only $18 \%$ of cases with Grampositive bacteria achieved that visual acuity. ${ }^{128}$

\section{Postintravitreal injection endophthalmitis}

Endophthalmitis cases following intravitreal injections have a high prevalence of more virulent Streptococcus species approximately 3 times more prevalent than in postoperative cases - resulting in relatively poorer visual outcomes. ${ }^{166} \mathrm{In}$ one series, $80 \%$ of the postinjection endophthalmitis cases caused by Streptococcus species had final visual outcome of HM or worse. ${ }^{84}$ Visual outcomes have varied among studies with the proportion of eyes returning to preinjection visual acuity in three recent studies ranging from $33 \%$ to $78 \%{ }^{84,167,168}$ Another study concluded that compared to postoperative endophthalmitis, postinjection endophthalmitis was 6 times more likely to have final visual acuity of count fingers (CF) or worse and was much less likely to have improvement in visual acuity following treatment. ${ }^{166}$

\section{Prophylaxis of endophthalmitis Postoperative endophthalmitis}

Endophthalmitis probably cannot be completely prevented, but its incidence may be reduced. The use of preoperative povidone-iodine antisepsis significantly reduces the rate of bacterial endophthalmitis. ${ }^{169}$ The European Society of Cataract and Refractive Surgeons (ESCRS) performed a large prospective randomized clinical trial, and reported that intracameral cefuroxime during phacoemulsification reduced the incidence of postoperative endophthalmitis by approximately 5 -fold. ${ }^{29}$ These results were replicated in later studies originating from different countries, ${ }^{170-174}$ although these results remain controversial and intracameral antibiotics are not universally employed even in Europe.

Multiple concerns have been raised about the use of prophylactic intracameral antibiotics. In the US, cefuroxime is not available in prepackaged form and must be reconstituted from powder in the operating room, creating risks of dilution errors and contamination. In addition, prophylactic use of antibiotics increases costs and contributes to increasing bacterial drug resistance. ${ }^{175}$

Similarly, the prophylactic role of topical antibiotics in postoperative endophthalmitis is unclear. While a 2007 survey from American Society of Cataract and Refractive Surgery (ASCRS) members reported that $88 \%$ of respondents used preoperative, $91 \%$ used perioperative, and $98 \%$ used postoperative topical antibiotics, ${ }^{176}$ no large-scale prospective studies have been performed to assess their efficacy. Preoperative topical antibiotics significantly reduce conjuctival flora ${ }^{177}$ but it is unclear whether this actually decreases the rate of postoperative endophthalmitis. One series reported that substituting a combination of postoperative topical 
antibiotics and corticosteroids with topical corticosteroids alone did not change the incidence of endophthalmitis. ${ }^{178}$

\section{Postintravitreal injection endophthalmitis}

An expert panel has recently reported updated guidelines for reducing the rate of endophthalmitis after intravitreal injections. ${ }^{179}$ As with postoperative endophthalmitis, povidoneiodine is effective in reducing endophthalmitis rates following intravitreal injections. ${ }^{180}$ Oral flora, including Streptococcus species, are more commonly isolated from postinjection cases than from postoperative cases. ${ }^{90}$ The routine use of surgical masks during intravitreal injections is logical ${ }^{181}$ but has not been reported to reduce endophthalmitis rates. ${ }^{182}$ The use of lid speculums has been traditionally recommended as part of a sterile protocol for administrating intravitreal injections. ${ }^{74,183}$ However, one series reported omitting lid speculums did not increase the rate of postinjection endophthalmitis. ${ }^{167}$

Numerous studies have reported that prophylactic antibiotics do not reduce the incidence of postintravitreal injection endophthalmitis. ${ }^{184,185}$ Furthermore, a meta-analysis of seven studies and 72,823 intravitreal injections found no statistically significant benefit in using postinjection antibiotics. ${ }^{186}$ Some series have reported that the use of topical antibiotics immediately after or for 5 days after injections were actually associated with higher rates of postinjection endophthalmitis, perhaps by altering conjunctival flora. ${ }^{187}$ In addition, several studies have reported that the use of prophylactic antibiotics for intravitreal injections contributes to emergence of antibiotic-resistant bacteria. ${ }^{188,189}$ It has been suggested that prophylactic antibiotics are not a necessary part of intravitreal injection preparation and management. ${ }^{129}$

\section{Posttraumatic endophthalmitis}

Antibiotic prophylaxis in posttraumatic endophthalmitis is controversial because there have been very few randomized clinical trials evaluating their effects. Systemic antibiotics have been widely utilized in open-globe injuries ${ }^{190}$ and nonuse of systemic antibiotics appears to be a risk factor for posttraumatic endophthalmitis. ${ }^{191,192}$ In a prospective, randomized study assessing the prophylactic effects of intracameral and intravitreal antibiotics in posttraumatic endophthalmitis, there was a statistically significant reduction in rates of endophthalmitis in antibiotic-treated eyes with IOFB. ${ }^{193}$

\section{Bleb-associated endophthalmitis}

There is little or no evidence that prophylactic topical antibiotics prevent bleb-associated endophthalmitis. On the contrary, it was reported that intermittent use or chronic use of antibiotics was associated with an increased risk of bleb-associated endophthalmitis ${ }^{66}$ Risk reduction of blebassociated endophthalmitis should include addressing its risk factors such as early treatment of blebitis ${ }^{194}$ and repair of leaking blebs. ${ }^{195}$

\section{Conclusion}

Endophthalmitis remains an important complication of surgery, injections, and trauma. The EVS provided important guidelines which remain relevant to this date. ${ }^{196}$ However, those guidelines were derived from cases of acute-onset postoperative endophthalmitis following cataract surgery and secondary IOL implantation and cannot be directly applied to other categories of endophthalmitis. Although it appears unlikely that large-scale randomized clinical trials will be performed on these other categories of endophthalmitis, management strategies continue to evolve by consensus and based on published clinical series.

Accurate identification of causative organisms of endophthalmitis is important, especially in patients who fail to respond to initial broad-spectrum therapy. Newer diagnostic techniques such as RT-PCR may provide more accurate and more sensitive results than traditional culture methods, although at the present time these techniques are not widely available outside of major medical centers.

The types of pathogens involved in infectious endophthalmitis and their antibiotic susceptibilities evolve over time, requiring periodic reassessment. At the present time, almost all isolates are susceptible to the combination of vancomycin and ceftazidime. ${ }^{159,160}$ As we continue to collect clinical trial data, treatment of endophthalmitis should continue to improve.

\section{Disclosure}

This study was partially supported by NIH Center Core Grant P30EY014801 and an unrestricted grant from Research to Prevent Blindness, New York, NY. Dr Schwartz has served on advisory boards for Alimera and Bausch + Lomb, and has received speakers' fees from ThromboGenics. The remaining authors have no financial disclosures.

\section{References}

1. Mamalis N. Endophthalmitis. J Cataract Refract Surg. 2002;28(5): 729-730.

2. Smith SR, Kroll AJ, Lou PL, Ryan EA. Endogenous bacterial and fungal endophthalmitis. Int Ophthalmol Clin. 2007;47(2):173-183.

3. Moloney TP, Park J. Microbiological isolates and antibiotic sensitivities in culture-proven endophthalmitis: a 15-year review. Br J Ophthalmol. 2014; 98(11):1492-1497. 
4. Verbraeken H. Treatment of postoperative endophthalmitis. Ophthalmologica. 1995;209(3):165-171.

5. Wykoff CC, Parrott MB, Flynn HW Jr, Shi W, Miller D, Alfonso EC. Nosocomial acute-onset postoperative endophthalmitis at a University Teaching Hospital (2002-2009). Am J Ophthalmol. 2010;150(3): 392.e2-398.e2.

6. Miller JJ, Scott IU, Flynn HW Jr, Smiddy WE, Newton J, Miller D. Acute-onset endophthalmitis after cataract surgery (2000-2004): incidence, clinical settings, and visual acuity outcomes after treatment. Am J Ophthalmol. 2005;139(6):983-987.

7. Ravindran RD, Venkatesh R, Chang DF, Sengupta S, Gyatsho J, Talwar B. Incidence of post-cataract endophthalmitis at Aravind Eye Hospital: outcomes of more than 42,000 consecutive cases using standardized sterilization and prophylaxis protocols. $J$ Cataract Refract Surg. 2009;35(4):629-636.

8. Freeman EE, Roy-Gagnon M-H, Fortin E, Gauthier D, Popescu M, Boisjoly H. Rate of endophthalmitis after cataract surgery in quebec, Canada, 1996-2005. Arch Ophthalmol. 2010;128(2):230-234.

9. Moshirfar M, Feiz V, Vitale AT, Wegelin JA, Basavanthappa S, Wolsey DH. Endophthalmitis after uncomplicated cataract surgery with the use of fourth-generation fluoroquinolones: a retrospective observational case series. Ophthalmology. 2007;114(4):686-691.

10. Jensen MK, Fiscella RG, Moshirfar M, Mooney B. Third- and fourthgeneration fluoroquinolones: retrospective comparison of endophthalmitis after cataract surgery performed over 10 years. J Cataract Refract Surg. 2008;34(9):1460-1467.

11. Friling E, Lundström M, Stenevi U, Montan P. Six-year incidence of endophthalmitis after cataract surgery: Swedish national study. J Cataract Refract Surg. 2013;39(1):15-21.

12. Keay L, Gower EW, Cassard SD, Tielsch JM, Schein OD. Postcataract surgery endophthalmitis in the United States: analysis of the complete 2003 to 2004 Medicare database of cataract surgeries. Ophthalmology. 2012;119(5):914-922.

13. Alharbi SS, Alrajhi A, Alkahtani E. Endophthalmitis following keratoplasty: incidence, microbial profile, visual and structural outcomes. Ocul Immunol Inflamm. 2013;22(3):218-223.

14. Taban M, Behrens A, Newcomb RL, Nobe MY, McDonnell PJ. Incidence of acute endophthalmitis following penetrating keratoplasty: a systematic review. Arch Ophthalmol. 2005;123(5):605-609.

15. Tay E, Bainbridge J, da Cruz L. Subretinal abscess after scleral buckling surgery: a rare risk of retinal surgery. Can J Ophthalmol. 2007;42(1): 141-142.

16. Al-Torbak AA, Al-Shahwan S, Al-Jadaan I, Al-Hommadi A, Edward DP. Endophthalmitis associated with the Ahmed glaucoma valve implant. Br J Ophthalmol. 2005;89(4):454-458.

17. Ramulu PY, Do DV, Corcoran KJ, Corcoran SL, Robin AL. Use of retinal procedures in medicare beneficiaries from 1997 to 2007. Arch Ophthalmol. 2010;128(10):1335-1340.

18. Govetto A, Virgili G, Menchini F, Lanzetta P, Menchini U. A systematic review of endophthalmitis after microincisional versus 20-gauge vitrectomy. Ophthalmology. 2013;120(11):2286-2291.

19. Kunimoto DY, Kaiser RS. Incidence of endophthalmitis after 20- and 25-gauge vitrectomy. Ophthalmology. 2007;114(12):2133-2137.

20. Eifrig CWG, Scott IU, Flynn HW Jr, Smiddy WE, Newton J. Endophthalmitis after pars plana vitrectomy: incidence, causative organisms, and visual acuity outcomes. Am J Ophthalmol. 2004;138(5): 799-802.

21. Shi X-Y, Zhao H-S, Wei W-B. Analysis of post-operative endophthalmitis after pars plana vitrectomy: a 10-year experience at a single center. Chin Med J (Engl). 2013;126(15):2890-2893.

22. Scott IU, Flynn HW Jr, Dev S, et al. Endophthalmitis after 25-gauge and 20-gauge pars plana vitrectomy: incidence and outcomes. Retina. 2008;28(1):138-142.

23. Park JC, Ramasamy B, Shaw S, et al. A prospective and nationwide study investigating endophthalmitis following pars plana vitrectomy: incidence and risk factors. Br J Ophthalmol. 2014;98(4):529-533. doi: 10.1136/bjophthalmol-2013-304485.
24. Endophthalmitis Vitrectomy Study Group. Results of the endophthalmitis vitrectomy study: a randomized trial of immediate vitrectomy and of intravenous antibiotics for the treatment of postoperative bacterial endophthalmitis. Arch Ophthalmol. 1995;113(12):1479-1496.

25. Park JC, Ramasamy B, Shaw S, et al. A prospective and nationwide study investigating endophthalmitis following pars plana vitrectomy: clinical presentation, microbiology, management and outcome. Br JOphthalmol. 2014;98(8):1080-1086. doi: 10.1136/bjophthalmol-2013-304486.

26. Hatch WV, Cernat G, Wong D, Devenyi R, Bell CM. Risk factors for acute endophthalmitis after cataract surgery: a population-based study. Ophthalmology. 2009;116(3):425-430.

27. Lalitha P, Rajagopalan J, Prakash K, Ramasamy K, Prajna NV, Srinivasan M. Postcataract endophthalmitis in South India: incidence and outcome. Ophthalmology. 2005;112(11):1884-1889.

28. West ES, Behrens A, McDonnell PJ, Tielsch JM, Schein OD. The incidence of endophthalmitis after cataract surgery among the U.S. Medicare population increased between 1994 and 2001. Ophthalmology. 2005; 112(8):1388-1394.

29. ESCRS Endophthalmitis Study Group. Prophylaxis of postoperative endophthalmitis following cataract surgery: results of the ESCRS multicenter study and identification of risk factors. $J$ Cataract Refract Surg. 2007;33(6):978-988.

30. Cao H, Zhang L, Li L, Lo S. Risk factors for acute endophthalmitis following cataract surgery: a systematic review and meta-analysis. PLoS One. 2013;8(8):e71731.

31. Menikoff JA, Speaker MG, Marmor M, Raskin EM. A case-control study of risk factors for postoperative endophthalmitis. Ophthalmology. 1991;98(12):1761-1768

32. Romero-Aroca P, Méndez-Marin I, Salvat-Serra M, Fernández-Ballart J, Almena-Garcia M, Reyes-Torres J. Results at seven years after the use of intracamerular cefazolin as an endophthalmitis prophylaxis in cataract surgery. BMC Ophthalmol. 2012;12(1):2.

33. García-Sáenz MC, Arias-Puente A, Rodríguez-Caravaca G, Bañuelos JB. Effectiveness of intracameral cefuroxime in preventing endophthalmitis after cataract surgery: ten-year comparative study. $J$ Cataract Refract Surg. 2010;36(2):203-207.

34. Pleyer U, Geldsetzer K. Prophylaxe der postoperativen infektiösen Endophthalmitis durch intrakamerale Cefuroximgabe - auf dem Weg zum Therapiestandard [Will intracameral cefuroxime become the new standard in endophtaalmitis prevention]? Klin Monbl Augenheilkd. 2008;225(11):934-940. German.

35. Lundström M, Wejde G, Stenevi U, Thorburn W, Montan P. Endophthalmitis after cataract surgery: a nationwide prospective study evaluating incidence in relation to incision type and location. Ophthalmology. 2007; 114(5):866-870.

36. Al-Mezaine HS, Kangave D, Al-Assiri A, Al-Rajhi AA. Acute-onset nosocomial endophthalmitis after cataract surgery: incidence, clinical features, causative organisms, and visual outcomes. J Cataract Refract Surg. 2009;35(4):643-649.

37. Li J, Morlet N, Ng JQ, Semmens JB, Knuiman MW. Significant nonsurgical risk factors for endophthalmitis after cataract surgery: EPSWA fourth report. Invest Ophthalmol Vis Sci. 2004;45(5):1321-1328.

38. Wallin T, Parker J, Jin Y, Kefalopoulos G, Olson RJ. Cohort study of 27 cases of endophthalmitis at a single institution. $J$ Cataract Refract Surg. 2005;31(4):735-741.

39. Aaberg TM Jr, Flynn HW Jr, Schiffman J, Newton J. Nosocomial acute-onset postoperative endophthalmitis survey: a 10-year review of incidence and outcomes. Ophthalmology. 1998;105(6):1004-1010.

40. Kunimoto DY, Das T, Sharma S, et al. Microbiologic spectrum and susceptibility of isolates: Part I. Postoperative endophthalmitis. Am J Ophthalmol. 1999;128(2):240-242.

41. Anand AR, Therese KL, Madhavan HN. Spectrum of aetiological agents of postoperative endophthalmitis and antibiotic susceptibility of bacterial isolates. Indian J Ophthalmol. 2000;48(2):123.

42. Johnson MW, Doft BH, Kelsey SF, et al. The endophthalmitis vitrectomy study: relationship between clinical presentation and microbiologic spectrum. Ophthalmology. 1997;104(2):261-272. 
43. Shirodkar AR, Pathengay A, Flynn HW Jr, et al. Delayed- versus acuteonset endophthalmitis after cataract surgery. Am J Ophthalmol. 2012; 153(3):391.e2-398.e2.

44. Al-Mezaine H, Al-Assiri A, Al-Rajhi A. Incidence, clinical features, causative organisms, and visual outcomes of delayed-onset pseudophakic endophthalmitis. Eur J Ophthalmol. 2008;19(5):804-811.

45. Fox GM, Joondeph BC, Flynn HW Jr, Pflugfelder SC, Roussel TJ. Delayed-onset pseudophakic endophthalmitis. Am J Ophthalmol. 1991; 111(2):163-173.

46. Brillat-Zaratzian E, Bron A, Aptel F, et al. FRIENDS Group: clinical and microbiological characteristics of post-filtering surgery endophthalmitis. Graefes Arch Clin Exp Ophthalmol. 2014;252(1):101-107.

47. Busbee BG, Recchia FM, Kaiser R, Nagra P, Rosenblatt B, Pearlman RB. Bleb-associated endophthalmitis: clinical characteristics and visual outcomes. Ophthalmology. 2004;111(8):1495-1503.

48. Song A, Scott IU, Flynn HW Jr, Budenz DL. Delayed-onset blebassociated endophthalmitis: clinical features and visual acuity outcomes. Ophthalmology. 2002;109(5):985-991.

49. Yamamoto T, Sawada A, Mayama C, et al. The 5-year incidence of bleb-related infection and its risk factors after filtering surgeries with adjunctive mitomycin $\mathrm{C}$ : collaborative bleb-related infection incidence and treatment study 2. Ophthalmology. 2014;121(5): 1001-1006.

50. Ciulla TA, Beck AD, Topping TM, Baker AS. Blebitis, early endophthalmitis, and late endophthalmitis after glaucoma-filtering surgery. Ophthalmology. 1997;104(6):986-995.

51. Yamamoto T, Kuwayama Y, Kano K, Sawada A, Shoji N; Study Group for the Japan Glaucoma Society Survey of Bleb-related Infection. Clinical features of bleb-related infection: a 5-year survey in Japan. Acta Ophthalmol. 2013;91(7):619-624.

52. Alwitry A, King AJ. Surveillance of late-onset bleb leak, blebitis and bleb-related endophthalmitis - a UK incidence study. Graefes Arch Clin Exp Ophthalmol. 2012;250(8):1231-1236.

53. DeBry PW, Perkins TW, Heatley G, Kaufman P, Brumback LC. Incidence of late-onset bleb-related complications following trabeculectomy with mitomycin. Arch Ophthalmol. 2002;120(3):297-300.

54. Greenfield DS, Suñer IJ, Miller MP, Kangas TA, Palmberg PF, Flynn HW Jr. Endophthalmitis after filtering surgery with mitomycin. Arch Ophthalmol. 1996;114(8):943-949.

55. Katz LJ, Cantor LB, Spaeth GL. Complications of surgery in glaucoma. Early and late bacterial endophthalmitis following glaucoma filtering surgery. Ophthalmology. 1985;92(7):959-963.

56. Solomon A, Ticho U, Frucht-Pery J. Late-onset, bleb-associated endophthalmitis following glaucoma filtering surgery with or without antifibrotic agents. J Ocul Pharmacol Ther. 1999;15(4):283-293.

57. Mochizuki K, Jikihara S, Ando Y, Hori N, Yamamoto T, Kitazawa Y. Incidence of delayed onset infection after trabeculectomy with adjunctive mitomycin C or 5-fluorouracil treatment. Br J Ophthalmol. 1997;81(10): 877-883.

58. Muckley ED, Lehrer RA. Late-onset blebitis/endophthalmitis: incidence and outcomes with mitomycin C. Optom Vis Sci. 2004;81(7): 499-504

59. Kuang T-M, Lin Y-C, Liu CJ-L, Hsu W-M, Chou C-K. Early and late endophthalmitis following trabeculectomy in a Chinese population. Eur J Ophthalmol. 2008;18(1):66-70.

60. Wallin Ö, Al-ahramy Abdullah M, Lundström M, Montan P. Endophthalmitis and severe blebitis following trabeculectomy. Epidemiology and risk factors; a single-centre retrospective study. Acta Ophthalmol. 2014;92(5):426-431

61. Ba'arah BT, Smiddy WE. Bleb-related endophthalmitis: clinical presentation, isolates, treatment and visual outcome of culture-proven cases. Middle East Afr J Ophthalmol. 2009;16(1):20-24.

62. Sharan S, Trope GE, Chipman M, Buys YM. Late-onset bleb infections: prevalence and risk factors. Can J Ophthalmol. 2009;44(3):279-283.

63. Ye H, Sun X, Gan D, et al. Bleb-associated endophthalmitis in a Chinese population (2003-2010): clinical characteristics and visual outcome. Eur J Ophthalmol. 2012;22(5):719-725.
64. Poulsen EJ, Allingham RR. Characteristics and risk factors of infections after glaucoma filtering surgery. J Glaucoma. 2000;9(6): 438-443.

65. Hori N, Mochizuki K, Ishida K, Yamamoto T, Mikamo H. [Clinical characteristics and risk factors of glaucoma filtering bleb infections]. Nihon Ganka Gakkai Zasshi. 2009;113(10):951-963. Japanese.

66. Jampel HD, Quigley HA, Kerrigan-Baumrind LA, Melia BM, Friedman D, Barron Y. Risk factors for late-onset infection following glaucoma filtration surgery. Arch Ophthalmol. 2001;119(7): 1001-1008.

67. Ashkenazi I, Melamed S, Avni I, Bartov E, Blumenthal M. Risk factors associated with late infection of filtering blebs and endophthalmitis. Ophthalmic Surg. 1991;22(10):570-574.

68. Kupin TH, Juzych MS, Shin DH, Khatana AK, Olivier MM. Adjunctive mitomycin $\mathrm{C}$ in primary trabeculectomy in phakic eyes. $\mathrm{Am} \mathrm{J}$ Ophthalmol. 1995;119(1):30-39.

69. Lehmann OJ, Bunce C, Matheson MM, et al. Risk factors for development of post-trabeculectomy endophthalmitis. Br JOphthalmol. 2000;84(12):1349-1353.

70. Rai P, Kotecha A, Kaltsos K, et al. Changing trends in the incidence of bleb-related infection in trabeculectomy. Br J Ophthalmol. 2012;96(7): 971-975.

71. Leng T, Miller D, Flynn HW Jr, Jacobs DJ, Gedde SJ. Delayed-onset bleb-associated endophthalmitis (1996-2008): causative organisms and visual acuity outcomes. Retina. 2011;31(2):344-352.

72. Fileta JB, Scott IU, Flynn HW Jr. Meta-analysis of infectious endophthalmitis after intravitreal injection of anti-vascular endothelial growth factor agents. Ophthalmic Surg Lasers Imaging Retina. 2014; 45(2):143-149.

73. Westfall AC, Osborn A, Kuhl D, Benz MS, Mieler WF, Holz ER. Acute endophthalmitis incidence: intravitreal triamcinolone. Arch Ophthalmol. 2005;123(8):1075-1077.

74. Moshfeghi DM, Kaiser PK, Scott IU, et al. Acute endophthalmitis following intravitreal triamcinolone acetonide injection. Am J Ophthalmol. 2003;136(5):791-796.

75. Bhavsar AR, Ip MS, Glassman AR; DRCRnet and the SCORE Study Groups. The risk of endophthalmitis following intravitreal triamcinolone injection in the DRCRnet and SCORE clinical trials. Am J Ophthalmol. 2007;144(3):454-456

76. Roth DB, Flynn HW Jr. Distinguishing between infectious and noninfectious endophthalmitis after intravitreal triamcinolone injection. Am J Ophthalmol. 2008;146(3):346-347.

77. Goldberg RA, Shah CP, Wiegand TW, Heier JS. Noninfectious inflammation after intravitreal injection of aflibercept: clinical characteristics and visual outcomes. Am J Ophthalmol. 2014;158(4): 733.e1-737.e1.

78. Chong DY, Anand R, Williams PD, Qureshi JA, Callanan DG. Characterization of sterile intraocular inflammatory responses after intravitreal bevacizumab injection. Retina. 2010;30(9):1432-1440.

79. Wickremasinghe SS, Michalova K, Gilhotra J, et al. Acute intraocular inflammation after intravitreous injections of bevacizumab for treatment of neovascular age-related macular degeneration. Ophthalmology. 2008;115(11):1911-1915.

80. Georgopoulos M, Polak K, Prager F, Prünte C, Schmidt-Erfurth U. Characteristics of severe intraocular inflammation following intravitreal injection of bevacizumab (Avastin). Br J Ophthalmol. 2009;93(4): $457-462$.

81. Sakamoto T, Ishibashi T, Ogura Y, et al. Survey of triamcinolonerelated non-infectious endophthalmitis. Nihon Ganka Gakkai Zasshi. 2011;115(6):523-528

82. Ahn SJ, Kim TW, Ahn J, Huh JW, Yu HG, Chung H. Associated factors and treatment outcome of presumed noninfectious endophthalmitis occurring after intravitreal triamcinolone acetonide injection. Graefes Arch Clin Exp Ophthalmol. 2013;251(3):715-723.

83. Irigoyen C, Ziahosseini K, Morphis G, Stappler T, Heimann H. Endophthalmitis following intravitreal injections. Graefes Arch Clin Exp Ophthalmol. 2012;250(4):499-505. 
84. Moshfeghi AA, Rosenfeld PJ, Flynn HW Jr, et al. Endophthalmitis after intravitreal vascular endothelial growth factor antagonists: a six-year experience at a university referral center. Retina. 2011;31(4): 662-668

85. Diago T, McCannel CA, Bakri SJ, Pulido JS, Edwards AO, Pach JM. Infectious endophthalmitis after intravitreal injection of antiangiogenic agents. Retina. 2009;29(5):601-605.

86. Mezad-Koursh D, Goldstein M, Heilwail G, Zayit-Soudry S, Loewenstein A, Barak A. Clinical characteristics of endophthalmitis after an injection of intravitreal antivascular endothelial growth factor. Retina. 2010;30(7):1051-1057.

87. Artunay O, Yuzbasioglu E, Rasier R, Sengül A, Bahcecioglu H. Incidence and management of acute endophthalmitis after intravitreal bevacizumab (Avastin) injection. Eye (Lond). 2009;23(12): 2187-2193.

88. Lyall DA, Tey A, Foot B, et al. Post-intravitreal anti-VEGF endophthalmitis in the United Kingdom: incidence, features, risk factors, and outcomes. Eye (Lond). 2012;26(12):1517-1526.

89. Entezari M, Ramezani A, Ahmadieh H, Ghasemi H. Batch-related sterile endophthalmitis following intravitreal injection of bevacizumab. Indian J Ophthalmol. 2014;62(4):468-471.

90. McCannel CA. Meta-analysis of endophthalmitis after intravitreal injection of anti-vascular endothelial growth factor agents: causative organisms and possible prevention strategies. Retina. 2011;31(4): 654-661.

91. Gordon DF, Jong BB. Indigenous flora from human saliva. Appl Microbiol. 1968;16(2):428-429.

92. Fan JC, Niederer RL, von Lany H, Polkinghorne PJ. Infectious endophthalmitis: clinical features, management and visual outcomes. Clin Experiment Ophthalmol. 2008;36(7):631-636.

93. Bhoomibunchoo C, Ratanapakorn T, Sinawat S, Sanguansak T, Moontawee K, Yospaiboon Y. Infectious endophthalmitis: review of 420 cases. Clin Ophthalmol. 2013;7:247-252.

94. Nicoară SD, Irimescu I, Călinici T, Cristian C. Outcome and prognostic factors for traumatic endophthalmitis over a 5-year period. J Ophthalmol. 2014;2014:747015.

95. Essex RW, Yi Q, Charles PGP, Allen PJ. Post-traumatic endophthalmitis. Ophthalmology. 2004;111(11):2015-2022.

96. Zhang Y, Zhang MN, Jiang CH, Yao Y, Zhang K. Endophthalmitis following open globe injury. Br J Ophthalmol. 2010;94(1):111-114.

97. Colyer MH, Weber ED, Weichel ED, et al. Delayed intraocular foreign body removal without endophthalmitis during Operations Iraqi Freedom and Enduring Freedom. Ophthalmology. 2007;114(8): 1439-1447.

98. Andreoli CM, Andreoli MT, Kloek CE, Ahuero AE, Vavvas D, Durand ML. Low rate of endophthalmitis in a large series of open globe injuries. Am J Ophthalmol. 2009;147(4):601.e2-608.e2.

99. Yang C-S, Lu C-K, Lee F-L, Hsu W-M, Lee Y-F, Lee S-M. Treatment and outcome of traumatic endophthalmitis in open globe injury with retained intraocular foreign body. Ophthalmologica. 2010;224(2): 79-85.

100. Faghihi H, Hajizadeh F, Esfahani MR, et al. Posttraumatic endophthalmitis: report No 2. Retina. 2012;32(1):146-151.

101. Dehghani AR, Rezaei L, Salam H, Mohammadi Z, Mahboubi M. Post traumatic endophthalmitis: incidence and risk factors. Glob $\mathrm{J}$ Health Sci. 2014;6(6):36634. doi: 10.5539/gjhs.v6n6p68.

102. Chaudhry IA, Shamsi FA, Al-Harthi E, Al-Theeb A, Elzaridi E, Riley FC. Incidence and visual outcome of endophthalmitis associated with intraocular foreign bodies. Graefes Arch Clin Exp Ophthalmol. 2008;246(2):181-186.

103. Li EYM, Chan TCY, Liu ATW, Yuen HKL. Low endophthalmitis rate and absence of sympathetic ophthalmia after open globe injuries - a ten-year review of open globe injury. J Clin Exp Ophthalmol. 2014; 5(328):2.

104. Alfaro DV, Roth D, Liggett PE. Posttraumatic endophthalmitis. Causative organisms, treatment, and prevention. Retina. 1994;14(3): 206-211.
105. Reynolds DS, Flynn HW Jr. Endophthalmitis after penetrating ocular trauma. Curr Opin Ophthalmol. 1997;8(3):32-38.

106. Parke DW, Pathengay A, Flynn HW Jr, Albini T, Schwartz SG. Risk factors for endophthalmitis and retinal detachment with retained intraocular foreign bodies. J Ophthalmol. 2012;2012:758526.

107. Thompson JT, Parver LM, Enger CL, Mieler WF, Liggett PE. Infectious endophthalmitis after penetrating injuries with retained intraocular foreign bodies. National Eye Trauma System. Ophthalmology. 1993; 100(10):1468-1474.

108. Long C, Liu B, Xu C, Jing Y, Yuan Z, Lin X. Causative organisms of post-traumatic endophthalmitis: a 20 -year retrospective study. $B M C$ Ophthalmol. 2014;14:34.

109. Jindal A, Pathengay A, Mithal K, et al. Endophthalmitis after open globe injuries: changes in microbiological spectrum and isolate susceptibility patterns over 14 years. J Ophthalmic Inflamm Infect. 2014;4(1):5.

110. Ahmed Y, Schimel AM, Pathengay A, Colyer MH, Flynn HW Jr. Endophthalmitis following open-globe injuries. Eye (Lond). 2012;26(2): 212-217.

111. Wong JS, Chan TK, Lee HM, Chee SP. Endogenous bacterial endophthalmitis: an east Asian experience and a reappraisal of a severe ocular affliction. Ophthalmology. 2000;107(8):1483-1491.

112. Puliafito CA, Baker AS, Haaf J, Foster CS. Infectious endophthalmitis. Review of 36 cases. Ophthalmology. 1982;89(8):921-929.

113. Shrader SK, Band JD, Lauter CB, Murphy P. The clinical spectrum of endophthalmitis: incidence, predisposing factors, and features influencing outcome. J Infect Dis. 1990;162(1):115-120.

114. Kresloff MS, Castellarin AA, Zarbin MA. Endophthalmitis. Surv Ophthalmol. 1998;43(3):193-224.

115. Krause L, Bechrakis NE, Heimann H, Kildal D, Foerster MH. Incidence and outcome of endophthalmitis over a 13-year period. Can JOphthalmol. 2009;44(1):88-94.

116. Lim HW, Shin JW, Cho HY, et al. Endogenous endophthalmitis in the Korean population: a six-year retrospective study. Retina. 2014; 34(3):592-602.

117. Binder MI, Chua J, Kaiser PK, Procop GW, Isada CM. Endogenous endophthalmitis: an 18-year review of culture-positive cases at a tertiary care center. Medicine (Baltimore). 2003;82(2):97-105.

118. Zhang H, Liu Z. Endogenous endophthalmitis: a 10-year review of culture-positive cases in northern China. Ocul Immunol Inflamm. 2010; 18(2):133-138.

119. Jackson TL, Paraskevopoulos T, Georgalas I. Systematic review of 342 cases of endogenous bacterial endophthalmitis. Surv Ophthalmol. Epub. June 18, 2014.

120. Schiedler V, Scott IU, Flynn HW Jr, Davis JL, Benz MS, Miller D. Culture-proven endogenous endophthalmitis: clinical features and visual acuity outcomes. Am J Ophthalmol. 2004;137(4):725-731.

121. Chung KS, Kim YK, Song YG, et al. Clinical review of endogenous endophthalmitis in Korea: a 14-year review of culture positive cases of two large hospitals. Yonsei Med J. 2011;52(4):630-634.

122. Leibovitch I, Lai T, Raymond G, Zadeh R, Nathan F, Selva D. Endogenous endophthalmitis: a 13-year review at a tertiary hospital in South Australia. Scand J Infect Dis. 2005;37(3):184-189.

123. Okada AA, Johnson RP, Liles WC, D'Amico DJ, Baker AS. Endogenous bacterial endophthalmitis. Report of a ten-year retrospective study. Ophthalmology. 1994;101(5):832-838.

124. Connell PP, O’Neill EC, Fabinyi D, et al. Endogenous endophthalmitis: 10-year experience at a tertiary referral centre. Eye (Lond). 2011;25(1): 66-72.

125. Essman TF, Flynn HW Jr, Smiddy WE, et al. Treatment outcomes in a 10-year study of endogenous fungal endophthalmitis. Ophthalmic Surg Lasers. 1997;28(3):185-194.

126. Shankar K, Gyanendra L, Hari S, Narayan SD. Culture proven endogenous bacterial endophthalmitis in apparently healthy individuals. Ocul Immunol Inflamm. 2009;17(6):396-399.

127. Lingappan A, Wykoff CC, Albini TA, et al. Endogenous fungal endophthalmitis: causative organisms, management strategies, and visual acuity outcomes. Am J Ophthalmol. 2012;153(1):162.e1-166.e1. 
128. Ness T, Pelz K, Hansen LL. Endogenous endophthalmitis: microorganisms, disposition and prognosis. Acta Ophthalmol Scand. 2007;85(8): 852-856.

129. Chen Y-J, Kuo H-K, Wu P-C, et al. A 10-year comparison of endogenous endophthalmitis outcomes: an east Asian experience with Klebsiella pneumoniae infection. Retina. 2004;24(3):383-390.

130. Forster RK, Abbott RL, Gelender H. Management of infectious endophthalmitis. Ophthalmology. 1980;87(4):313-319.

131. Kattan HM, Flynn HW Jr, Pflugfelder SC, Robertson C, Forster RK. Nosocomial endophthalmitis survey. Current incidence of infection after intraocular surgery. Ophthalmology. 1991;98(2):227-238.

132. Donahue SP, Kowalski RP, Jewart BH, Friberg TR. Vitreous cultures in suspected endophthalmitis. Biopsy or vitrectomy? Ophthalmology. 1993;100(4):452-455.

133. Barza M, Pavan PR, Doft BH, et al. Evaluation of microbiological diagnostic techniques in postoperative endophthalmitis in the Endophthalmitis Vitrectomy Study. Arch Ophthalmol 1997;115(9): 1142-1150.

134. Sandvig KU, Dannevig L. Postoperative endophthalmitis: establishment and results of a national registry. J Cataract Refract Surg. 2003;29(7) $1273-1280$

135. Rachitskaya AV, Flynn HW Jr, Wong J, Kuriyan AE, Miller D. A 10-year study of membrane filter system versus blood culture bottles in culturing vitrectomy cassette vitreous in infectious endophthalmitis. Am J Ophthalmol. 2013;156(2):349.e2-354.e2

136. Josephberg RG. Endophthalmitis: the latest in current management. Retina. 2006;26(6 Suppl):S47-S50.

137. Gokce G, Sobaci G, Ozgonul C. Post-traumatic endophthalmitis: a mini-review. Semin Ophthalmol. Epub February 27, 2014.

138. Patel SN, Langer PD, Zarbin MA, Bhagat N. Diagnostic value of clinical examination and radiographic imaging in identification of intraocular foreign bodies in open globe injury. Eur J Ophthalmol. 2012; 22(2):259-268

139. Moisseiev E, Last D, Goez D, Barak A, Mardor Y. Magnetic resonance imaging and computed tomography for the detection and characterization of nonmetallic intraocular foreign bodies. Retina. Epub July 30, 2014.

140. Cornut P-L, Boisset S, Romanet J-P, et al. Principles and applications of molecular biology techniques for the microbiological diagnosis of acute post-operative endophthalmitis. Surv Ophthalmol. 2014;59(3):286-303.

141. Ogawa M, Sugita S, Shimizu N, Watanabe K, Nakagawa I, Mochizuki M. Broad-range real-time PCR assay for detection of bacterial DNA in ocular samples from infectious endophthalmitis. Jpn J Ophthalmol. 2012; 56(6):529-535.

142. Bispo PJM, de Melo GB, Hofling-Lima AL, Pignatari ACC. Detection and gram discrimination of bacterial pathogens from aqueous and vitreous humor using real-time PCR assays. Invest Ophthalmol Vis Sci. 2011;52(2):873-881.

143. Ogawa M, Sugita S, Watanabe K, Shimizu N, Mochizuki M. Novel diagnosis of fungal endophthalmitis by broad-range real-time PCR detection of fungal 28S ribosomal DNA. Graefes Arch Clin Exp Ophthalmol. 2012;250(12):1877-1883.

144. Sugita S, Kamoi K, Ogawa M, Watanabe K, Shimizu N, Mochizuki M. Detection of Candida and Aspergillus species DNA using broad-range real-time PCR for fungal endophthalmitis. Graefes Arch Clin Exp Ophthalmol. 2012;250(3):391-398.

145. Lacroix C, Gicquel A, Sendid B, et al. Evaluation of two matrixassisted laser desorption ionization-time of flight mass spectrometry (MALDI-TOF MS) systems for the identification of Candida species Clin Microbiol Infect. 2014;20(2):153-158.

146. Seng P, Abat C, Rolain JM, et al. Identification of rare pathogenic bacteria in a clinical microbiology laboratory: impact of MALDI-TOF mass spectrometry. J Clin Microbiol. 2013;51(7):2182-2194. doi: 10.1128/JCM.00492-13.

147. Chung HJ, Castro CM, Im H, Lee H, Weissleder R. A magneto-DNA nanoparticle system for rapid detection and phenotyping of bacteria. Nat Nanotechnol. 2013;8(5):369-375.
148. Lott MN, Fuller JJ, Hancock HA, et al. Vitreal penetration of oral moxifloxacin in humans. Retina. 2008;28(3):473-476.

149. Hooper CY, Lightman SL, Pacheco P, Tam PMK, Khan A, Taylor SRJ. Adjunctive antibiotics in the treatment of acute bacterial endophthalmitis following cataract surgery. Acta Ophthalmol. 2012; 90(7):e572-e573.

150. Aldave AJ, Stein JD, Deramo VA, Shah GK, Fischer DH, Maguire JI. Treatment strategies for postoperative Propionibacterium acnes endophthalmitis. Ophthalmology. 1999;106(12):2395-2401.

151. Packer M, Chang DF, Dewey SH, et al. Prevention, diagnosis, and management of acute postoperative bacterial endophthalmitis. J Cataract Refract Surg. 2011;37(9):1699-1714.

152. Chaudhary KM, Romero JM, Ezon I, Fastenberg DM, Deramo VA. Pars plana vitrectomy in the management of patients diagnosed with endophthalmitis following intravitreal anti-vascular endothelial growth factor injection. Retina. 2013;33(7):1407-1416.

153. Prasad N, Latina MA. Blebitis and endophthalmitis after glaucoma filtering surgery. Int Ophthalmol Clin. 2007;47(2):85-97.

154. Sternberg P, Martin DF. Management of endophthalmitis in the post-endophthalmitis vitrectomy study era. Arch Ophthalmol. 2001; 119(5):754-755.

155. Sridhar J, Flynn HW Jr, Kuriyan AE, Miller D, Albini T. Endogenous fungal endophthalmitis: risk factors, clinical features, and treatment outcomes in mold and yeast infections. J Ophthalmic Inflamm Infect. 2013;3(1):60

156. Aaberg TM, Sternberg P Jr. Trauma: principles and techniques of treatment. In: Ryan S, Schachat A, Wilkinson C, Hinton D, Sadda S, Wiedeman P, editors. Retina. St Louis, MO: Mosby; 2001:2400-2426.

157. Mikosz CA, Smith RM, Kim M, et al. Fungal endophthalmitis associated with compounded products. Emerg Infect Dis. 2014;20(2):248-256.

158. Sheyman AT, Cohen BZ, Friedman AH, Ackert JM. An outbreak of fungal endophthalmitis after intravitreal injection of compounded combined bevacizumab and triamcinolone. JAMA Ophthalmol. 2013; 131(7):864-869.

159. Gentile RC, Shukla S, Shah M, et al. Microbiological spectrum and antibiotic sensitivity in endophthalmitis: a 25-year review. Ophthalmology. 2014;121(8):1634-1642.

160. Schimel AM, Miller D, Flynn HW Jr. Endophthalmitis isolates and antibiotic susceptibilities: a 10-year review of culture-proven cases. Am J Ophthalmol. 2013;156(1):50.e1-52.e1.

161. Lalwani GA, Flynn HW Jr, Scott IU, et al. Acute-onset endophthalmitis after clear corneal cataract surgery (1996-2005). Clinical features, causative organisms, and visual acuity outcomes. Ophthalmology. 2008; 115(3):473-476.

162. Maalouf F, Abdulaal M, Hamam RN. Chronic postoperative endophthalmitis: a review of clinical characteristics, microbiology, treatment strategies, and outcomes. Int J Inflamm. 2012;2012:313248.

163. Al-Turki TA, Al-Shahwan S, Al-Mezaine HS, Kangave D, Abu El-Asrar AM. Microbiology and visual outcome of bleb-associated endophthalmitis. Ocul Immunol Inflamm. 2010;18(2):121-126.

164. Lieb DF, Scott IU, Flynn HW Jr, Miller D, Feuer WJ. Open globe injuries with positive intraocular cultures: factors influencing final visual acuity outcomes. Ophthalmology. 2003;110(8):1560-1566.

165. Cornut P-L, Youssef EB, Bron A, et al. A multicentre prospective study of post-traumatic endophthalmitis. Acta Ophthalmol. 2013;91(5): 475-482.

166. Simunovic MP, Rush RB, Hunyor AP, Chang AA. Endophthalmitis following intravitreal injection versus endophthalmitis following cataract surgery: clinical features, causative organisms and post-treatment outcomes. Br J Ophthalmol. 2012;96(6):862-866.

167. Shah CP, Garg SJ, Vander JF, et al. Outcomes and risk factors associated with endophthalmitis after intravitreal injection of anti-vascular endothelial growth factor agents. Ophthalmology. 2011;118(10):2028-2034.

168. Nentwich MM, Yactayo-Miranda Y, Schwarzbach F, Wolf A, Kampik A, Mino de Kaspar H. Endophthalmitis after intravitreal injection: decreasing incidence and clinical outcome-8-year results from a tertiary ophthalmic referral center. Retina. 2014;34(5):943-950. 
169. Ciulla TA, Starr MB, Masket S. Bacterial endophthalmitis prophylaxis for cataract surgery: an evidence-based update. Ophthalmology. 2002;109(1):13-24.

170. Rahman N, Murphy CC. Impact of intracameral cefuroxime on the incidence of postoperative endophthalmitis following cataract surgery in Ireland. Ir J Med Sci. 2014:1-4

171. Ma B, Wu X, Lu W, Fan X, Luo M. Evaluation of intracameral cefuroxime injection for endophthalmitis prophylaxis following cataract surgery in a China ophthalmology department during 2009-2013. J Clin Exp Ophthalmol. 2014;5(344):2.

172. Shorstein NH, Winthrop KL, Herrinton LJ. Decreased postoperative endophthalmitis rate after institution of intracameral antibiotics in a Northern California eye department. J Cataract Refract Surg. 2013; 39(1):8-14.

173. Rodríguez-Caravaca G, García-Sáenz MC, Villar-Del-Campo MC, Andrés-Alba Y, Arias-Puente A. Incidence of endophthalmitis and impact of prophylaxis with cefuroxime on cataract surgery. J Cataract Refract Surg. 2013;39(9):1399-1403.

174. Barreau G, Mounier M, Marin B, Adenis J-P, Robert P-Y. Intracameral cefuroxime injection at the end of cataract surgery to reduce the incidence of endophthalmitis: French study. J Cataract Refract Surg. 2012;38(8):1370-1375.

175. Schimel AM, Alfonso EC, Flynn HW Jr. Endophthalmitis prophylaxis for cataract surgery: are intracameral antibiotics necessary? JAMA Ophthalmol. 2014; 132(11):1269-1270.

176. Chang DF, Braga-Mele R, Mamalis N, et al. Prophylaxis of postoperative endophthalmitis after cataract surgery: results of the 2007 ASCRS member survey. J Cataract Refract Surg. 2007;33(10): 1801-1805.

177. Vasavada AR, Gajjar D, Raj SM, Vasavada V, Vasavada V. Comparison of 2 moxifloxacin regimens for preoperative prophylaxis: prospective randomized triple-masked trial. Part 2: residual conjunctival flora. J Cataract Refract Surg. 2008;34(8):1383-1388.

178. Råen M, Sandvik GF, Drolsum L. Endophthalmitis following cataract surgery: the role of prophylactic postoperative chloramphenicol eye drops. Acta Ophthalmol. 2013;91(2):118-122.

179. Avery RL, Bakri SJ, Blumenkranz MS, et al. Intravitreal injection technique and monitoring: updated guidelines of an expert panel. Retina. In press.

180. Friedman DA, Mason JO, Emond T, Mcgwin G. Povidone-iodine contact time and lid speculum use during intravitreal injection: Retina. 2013;33(5):975-981.

181. Wen JC, McCannel CA, Mochon A, Garner OB. Bacterial dispersal associated with speech in the setting of intravitreous injections. Arch Ophthalmol. 2011;129(12):1551-1554.
182. Schimel AM, Scott IU, Flynn HW Jr. Endophthalmitis after intravitreal injections: Should the use of face masks be the standard of care? Arch Ophthalmol. 2011;129(12):1607-1609.

183. Scott IU, Flynn HW Jr. Reducing the risk of endophthalmitis following intravitreal injections. Retina. 2007;27(1):10-12.

184. Storey P, Dollin M, Pitcher J, et al. The role of topical antibiotic prophylaxis to prevent endophthalmitis after intravitreal injection. Ophthalmology. 2014;121(1):283-289.

185. Moss JM, Sanislo SR, Ta CN. A prospective randomized evaluation of topical gatifloxacin on conjunctival flora in patients undergoing intravitreal injections. Ophthalmology. 2009;116(8):1498-1501.

186. Dhoot SB, Kunjukunju N, Sabates N. The role of prophylactic antibiotic use in prevention of endophthalmitis following intravitreal injection of anti-vascular endothelial growth factor agents: a metaanalysis. Open J Ophthalmol. 2013;3(2):46-49.

187. Cheung CSY, Wong AWT, Lui A, Kertes PJ, Devenyi RG, Lam WC. Incidence of endophthalmitis and use of antibiotic prophylaxis after intravitreal injections. Ophthalmology. 2012;119(8):1609-1614.

188. Yin VT, Weisbrod DJ, Eng KT, et al. Antibiotic resistance of ocular surface flora with repeated use of a topical antibiotic after intravitreal injection. JAMA Ophthalmol. 2013;131(4):456-461.

189. Kim SJ, Toma HS. Antimicrobial resistance and ophthalmic antibiotics: 1-year results of a longitudinal controlled study of patients undergoing intravitreal injections. Arch Ophthalmol. 2011;129(9):1180-1188.

190. Narang S, Gupta V, Gupta A, Dogra MR, Pandav SS, Das S. Role of prophylactic intravitreal antibiotics in open globe injuries. Indian $J$ Ophthalmol. 2003;51(1):39-44.

191. Schmidseder E, de Kaspar HM, Kampik A, Klauß V. [Post-traumatic endophthalmitis after penetrating eye injury. Risk factors, microbiological diagnosis and functional outcome]. Ophthalmologe. 1998; 95(3):153-157. German.

192. Woodcock MGL, Scott RAH, Huntbach J, Kirkby GR. Mass and shape as factors in intraocular foreign body injuries. Ophthalmology. 2006;113(12):2262-2269.

193. Soheilian M, Rafati N, Mohebbi M, et al. Prophylaxis of acute posttraumatic bacterial endophthalmitis: a multicenter, randomized clinical trial of intraocular antibiotic injection, report 2. Arch Ophthalmol. 2007;125(4):460-465.

194. Reynolds AC, Skuta GL, Monlux R, Johnson J. Management of blebitis by members of the American Glaucoma Society: a survey. J Glaucoma. 2001;10(4):340-347.

195. Soltau JB, Rothman RF, Budenz DL, et al. Risk factors for glaucoma filtering bleb infections. Arch Ophthalmol. 2000;118(3):338-342.

196. Flynn HW Jr, Scott IU. Legacy of the Endophthalmitis Vitrectomy Study. Arch Ophthalmol. 2008;126(4):559-561.
Clinical Ophthalmology

\section{Publish your work in this journal}

Clinical Ophthalmology is an international, peer-reviewed journal covering all subspecialties within ophthalmology. Key topics include: Optometry; Visual science; Pharmacology and drug therapy in eye diseases; Basic Sciences; Primary and Secondary eye care; Patient Safety and Quality of Care Improvements. This journal is indexed on Submit your manuscript here: http://www.dovepress.com/clinical-ophthalmology-journal

\section{Dovepress}

PubMed Central and CAS, and is the official journal of The Society of Clinical Ophthalmology (SCO). The manuscript management system is completely online and includes a very quick and fair peer-review system, which is all easy to use. Visit http://www.dovepress.com/ testimonials.php to read real quotes from published authors. 